\title{
Licenciatura em Educação do Campo na UFT: perspectivas e desafios na
} construção de um curso

\author{
Darlene Araújo Gomes* \\ Idemar Vizolli** \\ Jocyléia Santana dos Santos***
}

\section{Resumo}

Socializamos uma pesquisa sobre a Licenciatura em Educação do Campo na Universidade Federal do Tocantins (UFT). Analisamos os processos de implantação em seus aspectos políticos e pedagógicos. Debatemos sobre o protagonismo dos movimentos sociais nas lutas pelo direito à educação e nas questões direcionadas às políticas de Educação Superior para o meio rural no Brasil. No percurso metodológico, inspiramo-nos na História Oral, na perspectiva da abordagem qualitativa. Entrevistamos docentes que vivenciam o processo de implantação do curso na UFT, para apreender as expectativas e construções empreendidas na materialização da Licenciatura. A fundamentação teórica deste estudo se deu mediante o diálogo com diversos teóricos como: Caldart, Santos, Molina, Arroyo, Silva, Alberti. Discorremos sobre a Pedagogia da Alternância como referência para a alternância pretendida para a Licenciatura em Educação do Campo, assim como as proposituras para a sua efetivação. Depreendemos que a implantação da Licenciatura em Educação do Campo configura uma conquista para a população que vive no e do campo e encontra-se em processo de construção, que demanda, por parte dos seus executores, novas posturas em frente aos conflitos e enfrentamentos para a sua efetiva materialização.

Palavras-chave: Licenciatura. Educação do Campo. Alternância.

\footnotetext{
${ }^{1}$ Mestra em Educação pela Universidade Federal do Tocantins (UFT). Professora substituta da Universidade do Estado de Pará (UEPA).

2 Doutor em Educação pela Universidade Federal do Paraná (UFPR). Professor do Programa de Pós-Graduação em Educação da Universidade Federal do Tocantins (UFT).

${ }^{3}$ Doutora em História pela Universidade Federal do Pernambuco (UFPE). Professora do Programa de Pós-Graduação em Educação da Universidade Federal do Tocantins (UFT).
} 


\section{Introdução}

Os cursos de Licenciatura em Educação do Campo (LEdoC) fazem parte das políticas públicas para a Educação do Campo. Apresentam-se como uma experiência que pretende desenvolver um programa de formação para professores que atuam nos anos finais do Ensino Fundamental e Ensino Médio nas escolas do campo, preparando os educadores para uma atuação profissional "que vá para além da docência, e dê conta da gestão dos processos educativos que acontecem na escola e em seu entorno". ${ }^{1}$

Apresentando-se como contribuinte na discussão sobre essa experiência, este $\operatorname{artigo}^{2}$ traz os resultados de uma pesquisa sobre a implantação do LEdoC na Universidade Federal do Tocantins (UFT), nos campi de Arraias e Tocantinópolis, tendo como objetivo investigar os percursos e desafios encontrados para sua materialização.

A pesquisa se desenvolveu por meio da análise do Projeto Político-Pedagógico (PPP) dos cursos de LEdoC e da realização de entrevistas semiestruturadas com cinco professores que participaram da implementação do curso. Optou-se também pela metodologia da História Oral (SANTOS; ARAÚJO, 2007), que se situa na perspectiva da abordagem qualitativa.

Tal opção metodológica se deu pelo fato de que a História Oral oportuniza o estudo das percepções pessoais, como permite também a aproximação do pesquisador com o objeto investigado, contribuindo, teoricamente, na interpretação das histórias narradas pelos sujeitos investigados.

Compreendemos que a narrativa destes sujeitos trazem importantes contribuições no sentido de entender como a proposta do curso está sendo construída, bem como quais são seus elementos constitutivos, tendo em vista os propósitos da Educação do Campo e o fato de ser a primeira experiência no Ensino Superior do estado do Tocantins.

\section{A LEdoC e os movimentos sociais}

Para começo de conversa, faz-se necessário mencionar que a LEdoC é um novo curso de graduação e vem sendo implantado nas universidades públicas brasileiras com apoio do Ministério da Educação (MEC), via edital de chamada pública do Programa de Apoio à Formação Superior em Licenciatura em Educação do Campo (Procampo). O programa, aprovado pelo MEC em 2006, é coordenado e executado pela Secretaria de Educação Continuada, Alfabetização, Diversidade e 
Inclusão (Secadi) com a colaboração da Secretaria de Educação Superior (SESu) e o Fundo Nacional de Desenvolvimento da Educação (FNDE).

Segundo Molina (2015), a implantação dessa Licenciatura iniciou-se com uma experiênciapiloto, com a construção de quatro cursos, em 2007, em instituições universitárias indicadas pelos movimentos sociais ligados à Educação do Campo: Universidade de Brasílica (UnB); Universidade Federal da Bahia (UFBA); Universidade Federal de Minas Gerais (UFMG) e a Universidade Federal de Sergipe (UFS).

Após essas experiências, outras instituições participaram dos editais de convocação seguintes (2008, 2009 e 2012), apresentando projetos, e de lá para cá houve um aumento significativo de instituições públicas que ofertam o curso, ultrapassando o número de 40 (quarenta) universidades que enfrentam os desafios de sua implantação.

Em seus estudos, Silvanete Pereira dos Santos (2012, p.79) destaca que esta Licenciatura “expressa o compromisso social da universidade com a preparação dos sujeitos para o exercício da vida cotidiana". No entanto, como frisa a autora,

[o] conhecimento produzido no espaço acadêmico só terá sentido, na produção da vida dos sujeitos que nele transitam, se servir para conhecerem um pouco mais de si mesmos e do mundo que os cerca. Fora dessa compreensão, o conhecimento científico perde seu princípio básico que é construir respostas para problemas reais, de sujeitos reais inseridos no processo histórico das construções humanas. (SANTOS, S. P., 2012, p. 79).

A autora ressalta ainda que a luta dos Movimentos Sociais pela inserção da classe camponesa no Ensino Superior está em consonância com a construção do olhar sobre o direito à educação. Segundo ela, a luta por Reforma Agrária objetiva mais do que o acesso à terra; demanda também o fortalecimento da agricultura camponesa, que representa a forma de viver e produzir a vida de um povo, fortalecendo a defesa de uma educação pública com desenvolvimento social, cultural e econômico do campo. Para a autora, a luta pela garantia da Educação Superior é mais uma forma de o povo camponês mostrar ao país que ele existe e sabe resistir à força hegemônica.

Essa intencionalidade é manifestada pela mobilização e entrada dos movimentos do campo na luta pelo direito à educação e nas disputas pelo espaço acadêmico de produção do saber, mostrando assim seu papel contra-hegemônico no debate sobre a construção de um novo projeto de campo e de país, delineando novas formas de a universidade repensar o seu papel social (MOLINA; SÁ 2013).

Em observância às especificidades dos povos do campo, as Diretrizes Operacionais para a Educação Básica nas Escolas do Campo, Resolução no 1 do Conselho Nacional de Educação, Câmara de Educação Básica (CNE/CEB), de 3 de abril de 2002, em seu artigo 6º preveem que o poder público 
- em regime de colaboração entre União, os Estados, o Distrito Federal e os Municípios proporcionará Educação Infantil e Ensino Fundamental às comunidades rurais, inclusive para aqueles que não os concluíram na idade prevista, cabendo, em especial aos Estados, garantir as condições para o acesso ao Ensino Médio e à Educação Profissional de Nível Técnico.

As Diretrizes constituem um importante marco das lutas, conquistas e reivindicações dos movimentos sociais. Preconizam a ampliação da rede de escolas públicas que ofertem a Educação Básica para a população que vive no e do campo, com vistas à criação de alternativas curriculares e ao trabalho docente, já que propõem a oferta dos anos finais do Ensino Fundamental e do Ensino Médio.

Caldart (2011) afirma que, do ponto de vista dos movimentos, a proposição do curso de LEdoC insere-se neste contexto, pois garante a formação específica para atuação docente nesses contextos sociais do campo.

Para Clarice Aparecida Santos (2009), na proposição da LEdoC, os movimentos sociais incorporaram a cultura desenvolvida no Programa Nacional de Educação na Reforma Agrária (Pronera), no que se refere à entrada de turmas específicas. A entrada coletiva, que já se encontra como prática estabelecida no âmbito do Programa e, recentemente, na LEdoC, está de acordo com a concepção de direito que a move, porque os "camponeses e camponesas e suas organizações constituem-se sujeitos coletivos de direitos, e assim querem institucionalizar-se" (SANTOS, C. A., 2009, p. 89).

Seguindo essa linha de raciocínio, os cursos de formação de educadores do campo desenvolvidos pelas universidades, na perspectiva dos movimentos sociais, devem estar vinculados a um projeto político de transformação social, comprometidos com a função social de produzir conhecimento enquanto possibilidade para emancipação humana. Assim, à universidade cabe o desafio de repensar seu fazer pedagógico, ainda que não represente uma total mudança de paradigma. Deste modo, a oferta de cursos de nível superior direcionados aos povos do campo representa um reforço às contradições coexistentes dentro da universidade (MOLINA; SÁ, 2011).

\section{Bases Pedagógicas da LEdoC}

A formação de professores do campo é condição necessária para a qualidade da educação e deve estar comprometida com a história, a cultura e os valores do meio rural. A oferta de cursos de licenciatura específica para a docência no e do campo instaura um novo elemento no âmbito da discussão teórica acerca da "Educação Superior" e sua relação com a "Educação do Campo". 
De acordo com Molina e Sá (2011, p. 39), a Educação do Campo deve "compreender os processos culturais, as estratégias de socialização, as relações de trabalho vividas pelos sujeitos do campo em suas lutas cotidianas para manterem esta identidade como elementos essenciais do processo formativo".

Para Caldart (2011, p. 104), existem tensões no encontro entre a Educação do Campo e uma Licenciatura. Em primeiro lugar, porque a configuração legal e institucional das licenciaturas que estão postas no sistema educacional expressa uma concepção de formação de educadores de escola que “diverge dos debates originários da Educação do Campo”. Em segundo, porque os sujeitos envolvidos (movimentos sociais, governos e universidades) "não têm, em seu conjunto, os mesmos interesses e objetivos e nem a mesma dinâmica de atuação".

Caldart (2011, p. 104) menciona alguns desafios postos à implantação do curso, dentre eles destaca "o tratamento a ser dado ao foco da profissionalização do curso", tendo em vista que o "objeto central da Licenciatura em Educação do Campo é a escola de Educação Básica”.

Outro desafio apontado pela autora consiste em criar estratégias pedagógicas que viabilizem o exercício da práxis no interior do próprio curso, ou seja, que possibilitem ao educador o desenvolvimento da teoria e prática em um mesmo movimento, que é "o de transformação da realidade (do mundo) e de sua autotransformação humana, de modo que esteja preparado para ajudar a desencadear esse mesmo movimento nos processos educativos de que participe" (CALDART, 2011, p. 104).

Ainda, faz-se salutar construir novas referências para a Escola do Campo, partindo das práticas desenvolvidas no interior do próprio curso ou a propósito dele, ou seja, fazer com que a organização do trabalho pedagógico possa servir de parâmetro para repensar/refazer a forma escolar presente (ou ausente) hoje no campo constitui a maior tarefa do curso.

Uma das características mais marcantes do curso de LEdoC é a configuração de uma nova organização do trabalho pedagógico, voltada para as escolas de Ensino Fundamental (séries finais) e Médio, para a atuação educativa em equipe e docência multidisciplinar, por áreas do conhecimento.

No que tange ao perfil profissional projetado para o curso LEdoC, Caldart (2011, p. 99) aponta três conjuntos de aprendizagens básicas de formação de educadores do campo:

1) Docência multidisciplinar em uma das áreas de conhecimento propostas pelo curso: Linguagens, Artes e Literatura; Ciências Humanas e Sociais; Ciências da Natureza e Matemática; Ciências Agrárias;

2) Gestão dos processos educativos escolares, compreendidos como formação para educação dos sujeitos das diferentes etapas e modalidades da Educação Básica, para 
a construção do projeto político-pedagógico e para a organização do trabalho escolar e pedagógico nas escolas do campo;

3) Atuação nas comunidades rurais, o que requer uma preparação específica para o trabalho pedagógico com as famílias e ou grupos sociais de origem dos estudantes, para liderança de equipes e para implementação (técnica e organizativa) de projetos de desenvolvimento sustentável.

Sobre a formação dos educadores do campo, Molina e Sá (2011, p. 48) acrescentam que a habilitação de docentes por área de conhecimento tem como um dos seus objetivos ampliar as possibilidades de oferta da "Educação Básica no campo, especialmente no que diz respeito ao Ensino Médio, pensando em estratégias que maximizem a possibilidade das crianças e jovens do campo estudarem em suas localidades de origem". As autoras evidenciam a importância de se fazer a articulação entre as dimensões racionais e acadêmicas, por meio da construção de saberes oriundos de uma postura interdisciplinar.

Nessa acepção, torna-se indispensável a ruptura com a concepção do currículo compartimentado, descontextualizado, fragmentado, que não propicia a construção e a compressão de nexos que permitam a sua estruturação com base na realidade. Portanto, na construção de uma proposta curricular, "[...] é preciso levar em consideração que existem diferentes classes de conhecimentos e que cada uma delas é reflexo de determinados propósitos, perspectivas, experiências, valores e interesses humanos" (SANTOMÉ, 1998, p. 100).

\section{Os espaços de formação do educador do campo: alternância no Ensino Superior}

A alternância na LEdoC pode ser compreendida como uma estratégia de organização curricular, com vistas a promover a articulação entre educação e a realidade específica das populações do campo, permitindo o acesso e a permanência aos professores em exercício; além de não condicionar o ingresso de jovens e adultos na Educação Superior à alternativa de deixar de viver no campo.

De acordo com Molina e Sá (2011), os princípios do processo da metodologia da alternância foram incorporados a partir das experiências do movimento da Educação do Campo, com base nos fundamentos político-epistemológicos da pedagogia dos movimentos socais. As autoras afirmam ainda que a concepção de alternância proposta na LEdoC visa integrar a atuação dos sujeitos educandos na construção do "conhecimento necessário à sua formação de educadores, nos diferentes tempos formativos, organizados a organizados a partir do Tempo Escola - TE e Tempo Comunidade - TC" (MOLINA; SÁ, 2011, p. 44). 
Para Barbosa (2012, p. 144), as dimensões da formação humana, das relações sociopolíticas e culturais, das relações de produção do conhecimento na LEdoC dizem respeito a todos os sujeitos que tecem a práxis educativa, docentes e educandos, pois o "pressuposto é que o curso seja um espaço de formação humana, não apenas de instrução, o lugar de estudar, mas de vida, em que todas as dimensões humanas devem ter o seu lugar". Desta forma, a autora argumenta que o trabalho pedagógico não deve se limitar apenas ao tempo da aula, ou seja, o tempo de instrução, mas sim visar ao desenvolvimento da totalidade das dimensões humanas, que vai além de uma essência humana abstrata, ou seja, de um ser humano engendrado nas relações sociais, tendo como fundamento o trabalho.

Outro aspecto a ser considerado na alternância é a ruptura do paradigma dominante no ensino e na pesquisa, que considera a realidade como exemplo ilustrativo da ciência. Como afirmam Molina e Sá (2011, p. 43), "no caso da formação do educador do campo, trata-se de colocar a realidade como centro em torno do qual as ciências e outras formas de conhecimento se articulam, para que a realidade possa ser não apenas compreendida e pensada, mas transformada".

Assim concebida e defendida, a alternância tem sido importante instrumento para a ressignificação dos espaços de ensino e aprendizagem dentro da academia, pois a organização dos estudos por tempos alternados democratizam o acesso à educação a muitos sujeitos que não teriam condições de fazer um curso superior no modelo predominante ofertado pelas universidades públicas brasileiras.

Neste contexto, a docência desempenha um importante papel na práxis pedagógica do curso, na mediação dos processos de construção e reconstrução dos percursos didático-metodológicos previstos na matriz curricular da LEdoC, na qual o conhecimento do educador do campo vai sendo construído a partir dos saberes e questões constituídos nos tempos educativos da alternância - Tempo Escola (TE) e Tempo Comunidade (TC).

Esses tempos educativos contribuem para o desenvolvimento dos projetos de LEdoC, na medida em que conduzem a uma necessidade de reflexão por parte dos sujeitos envolvidos na sua práxis pedagógica. A ação-reflexão-ação possibilita o movimento dialético necessário para a efetivação da proposta e constitui um desafio na adoção de uma metodologia específica, contrária à adotada nos cursos regulares da universidade brasileira.

\section{A Licenciatura em Educação do Campo na UFT: uma proposta em construção}


Como já citado, o número de LEdoCs cresceu consideravelmente na última década e hoje passa de quatro dezenas. Instituições pelo país acreditam na proposta e participam desse processo de implantação; entre elas podemos citar a Universidade Federal do Tocantins, que oferta a Licenciatura em dois de seus campi: Arraias e Tocantinópolis.

Os cursos desses campi foram criados a partir da iniciativa de um coletivo de educadores que, em resposta ao Edital Chamada Pública $n^{\circ}$ 2, da Secadi, de 3 de agosto de 2012, propuseram-se a formular os PPPs do Curso. Depois de muitos debates, reuniões, crenças e descrenças por parte dos seus elaboradores, o processo culminou com a criação dos documentos que ora nos propomos a analisar, os quais, de antemão, afirmamos estarem em processo de "construção", à medida que se efetivam na prática.

Esse processo de implantação é ímpar - como boa parte dessas licenciaturas, em virtude das especificidades de cada local - e merece ser registrado e discutido. Assim, apresentamos aqui alguns momentos e discussões desse processo ouvindo seus protagonistas.

Nesse intento, a pesquisa deu-se em dois momentos: o primeiro, refere-se à análise dos Projetos Pedagógicos dos Cursos (PPCs) da LEdoC, dos campi de Arraias e Tocantinópolis, a fim de identificar elementos, proposições e estratégias para a formação de educadores do campo.

No segundo momento, buscamos apreender, das histórias narradas pelos sujeitos entrevistados, que estão vivenciando o processo de implementação do Curso, as percepções, os desafios e enfrentamentos encontrados na materialização, na academia, de um novo modelo de construção e apropriação do conhecimento.

A nossa análise se baseou na perspectiva de identificar elementos, proposições e estratégias na construção da proposta de formação de professores na LEdoC. Em muitos aspectos, os elaboradores de ambos os documentos (PPCs de Arraias e Tocantinópolis) optaram por um texto comum, válido para os dois campi, porém diferente em alguns pontos, que dizem respeito à singularidade de cada unidade formativa, observando as diferentes concepções que orientam a prática desses sujeitos.

Os elaboradores dos PPCs disponibilizaram suas experiências e convicções na formulação da proposta da LEdoC, que foi concretizada com o ingresso das primeiras turmas, nos campi de Arraias e Tocantinópolis, no segundo semestre de 2014. O curso da LEdoC da UFT foi estruturado da seguinte forma:

- Nome do Curso: Licenciatura em Educação do Campo;

- Habilitação: Códigos e Linguagens - Artes e Música;

- Modalidade: Licenciatura - Ensino Presencial;

- Número de vagas: 120 vagas/ano em uma entrada em processo seletivo organizado pela [Comissão Permanente de Seleção]COPESE-UFT; 
- Duração do Curso: Mínimo: 8 semestres/Máximo: 16 semestres;

- Forma de Acesso: Processo seletivo - vestibular - de acordo com Edital específico da UFT;

- Regime Letivo: Bloco Semestral;

- Carga Horária Total Do Curso: Carga Horária Total: 3.610 horas/Disciplinas do Ciclo Básico: 1.860 horas/Disciplinas do Ciclo Profissional: 1.200 horas/Atividades Complementares: 200 horas/Estágios Curriculares Supervisionados: 400 horas. (UFT, 2013a, p. 14; 2013b, p. 14).

Ao encampar o desafio de implantar a LEdoC, a UFT também busca romper com o paradigma de educação rural, com a construção de uma formação teórica e prática que conduza os sujeitos do campo à emancipação. Sobre esse processo, Boaventura de Sousa Santos (2011, p. 257) menciona que uma transição paradigmática é ambiente de incertezas, de "complexidade e de caos, que repercute nas estruturas e nas práticas sociais, nas instituições e nas ideologias, nas representações sociais e na inteligibilidade, na vida vivida e na personalidade". O autor salienta que transpor a transição paradigmática repercute tanto nos dispositivos da regulação social como nos da emancipação social.

Neste sentido, a LEdoC, como um novo modelo propositivo de formação de educadores, difere em concepção e forma dos cursos ofertados na academia, cujos pilares ainda estão sendo construídos.

Os PPCs (2013) analisados trazem em sua estrutura a defesa de que a formação superior específica em Educação do Campo pretende promover a oferta da Educação Básica nas comunidades rurais, com vistas a atender às demandas apresentadas no campo, nas localidades onde há carência de professores qualificados para o ensino em diversas áreas do conhecimento, incluindo Artes e Música.

Em Tocantinópolis, uma ação efetiva para a demanda do curso foi debatida nas reuniões e fóruns de Educação do Campo coordenados pelos movimentos sociais e o campi. Em 2012, foi realizada a Conferência em Educação do Campo, com o tema "Políticas públicas e Educação do Campo no Tocantins"; como produto das reflexões, ficou definido em agenda do Fórum a criação de curso de Ensino Médio (Secretaria de Estado de Educação Esporte e Lazer - Seduc/Pronera) e graduação em Educação do Campo (UFT, 2013b, p. 18).

Podemos observar que a implantação da LEdoC em Tocantinópolis contou com a participação efetiva dos movimentos sociais, visto que, pela própria característica da região, eles são ativos. Neste sentido, a UFT buscou atender e legitimar as demandas por uma Educação do Campo pautada nas reivindicações dos movimentos sociais.

Consta no PPC de Arraias (2013, p. 16) que a efetivação da proposta partiu de "articulações já existentes com a rede de ensino, com os projetos de extensão e pesquisa, com as comunidades rurais da região, bem como as relações já estabelecidas com as associações comunitárias rurais”. As discussões 
com estes segmentos da sociedade, além das realizadas no contexto da academia, possibilitaram a realização da proposta.

Dada a realidade concreta em que se situam os campi de Arraias e Tocantinópolis, cada equipe de educadores se dedicou a construir os documentos em estudo, de acordo com suas concepções e convicções. Os PPCs expressam intencionalidades comuns a ambos, nos aspectos mais abrangentes e definidores da LEdoC, em sentido geral, e específicas, quando relacionadas às concepções e convicções de seus elaboradores. Entretanto essas diferentes concepções serão mais contundentes quando narradas pelos seus elaboradores.

Sobre esse processo de implantação de cursos de formação superior para professores para a Educação do Campo, Meneses (2009, p. 95) faz a seguinte observação:

Não podemos ser ingênuos e pensar que essa assunção se dá sem debates, descrenças e mesmo desavenças entre os pares na academia. Vencida essa barreira, na elaboração dos projetos - primeiro passo de cada curso - estas Universidades, através de seus professores que compreendem a responsabilidade da instituição com a comunidade, não só a comunidade dita acadêmica, mas com a sociedade, habilitam-se através de seu histórico a desenvolver esses cursos.

Com base nestes pressupostos, a construção do projeto político-pedagógico para o curso de LEdoC demanda a busca por caminhos que superem a perspectiva disciplinar das construções curriculares para a concepção de currículos integrados, por meio de seus eixos transversais e interdisciplinares, com vistas a alcançar a transdisciplinaridade.

A realidade como base da produção do conhecimento e a prática social como ponto de partida e chegada permeiam a articulação entre os conhecimentos científicos e os conhecimentos empíricos, ao propor-se a alternância dos tempos formativos como base metodológica. Caldart (2011) explica que os processos formativos da LEdoC devem estar orientados por uma concepção de educação e de escola ligadas aos objetivos da classe trabalhadora, fundamentados em uma abordagem histórica-dialética de compreensão da realidade e do modo de produção do conhecimento.

Nesta perspectiva, depreende-se das intencionalidades contidas nos objetivos da LEdoC da UFT a responsabilidade e o compromisso com a Educação do Campo, ao formar educadores para uma população específica, que historicamente foi negligenciada pelas políticas públicas educacionais.

Os PPCs analisados expressam que o maior desafio na UFT, no que diz respeito à implementação de novos currículos, encontra-se no desejado de avançar e jaz na construção de uma matriz curricular referenciada e justificada pela ação e interação dos seus construtores: com "ênfase não linear, nos conduzirá a arquiteturas de formação não determinista, com possibilidades de abertura, o 
que propiciará o nosso projeto de interdisciplinaridade, flexibilidade e mobilidade” (UFT, 2013a, p. 23; 2013b, p. 24).

No que diz respeito às políticas de acesso, os PPCs apontam que a necessidade de se formar professores para a Educação do Campo faz com que, ao delinear-se o perfil do estudante do Curso de LEdoC, leve-se em consideração ações afirmativas para a correção histórica da desigualdade sofrida pelos povos do campo. Para tanto, a oferta de vagas visa atender preferencialmente educadores de escolas públicas de Educação Básica do campo em efetivo exercício nos anos finais do Ensino Fundamental ou Médio; pessoas que atuam como educadores ou coordenadores nas escolas voltadas para a escolarização básica da educação de jovens e adultos (Ensino Fundamental ou Ensino Médio) em comunidades camponesas; pessoas que atualmente coordenam ou fazem o acompanhamento político-pedagógico dos cursos formais apoiados pelo Pronera; jovens e adultos de comunidades do campo ou que com ele se identifiquem (UFT, 2013a, p. 95; 2013b, p. 96).

Somados a estes elementos e especificidades, estão os critérios e instrumentos do vestibular da UFT, quando de sua seleção da primeira turma, publicados no Edital n ${ }^{\circ}$ 8, de 4 de fevereiro de 2014. O vestibular foi exclusivo para a licenciatura em tela, para que a divulgação fosse específica, assim como seu processo de acesso.

Desta forma, o acesso ao Ensino Superior para os sujeitos do campo, na perspectiva da LEdoC, constitui-se em uma ferramenta para a formação de educadores que tenham uma atitude crítica e criativa, que os conduza à produção de novas interpretações e propostas de intervenção social.

Assim, a proposição diferenciada da LEdoC possibilita o ingresso de sujeitos que, de acordo com o perfil delineado, dificilmente chegariam à universidade nos cursos "regulares" já institucionalizados.

\section{Os Testemunhos Ressignificados}

A partir da análise dos itinerários formativos contidos nos PPCs da LEdoC da UFT, buscamos, neste momento, identificar os entrelaçamentos existentes entre estes itinerários e as narrativas dos sujeitos entrevistados, que vivenciam a implementação do curso, considerando que a memória dos sujeitos constituirá sempre a primeira fonte para a História Oral.

Oportuno mencionar que, a princípio, pensamos que o recorte histórico muito recente não atenderia aos requisitos para a escolha de tal metodologia, porém concluímos que este momento precisa 
ser registrado, e as narrativas dos sujeitos protagonistas poderão, no futuro, ser referência para novos percursos e novas caminhadas na implementação da LEdoC.

Compartilhamos com Delgado (2003, p. 10) o entendimento de que "o olhar do homem no tempo e através do tempo traz em si a marca da historicidade. São os homens que constroem suas visões e representações das diferentes temporalidades e acontecimentos que marcaram sua própria história".

O paradigma da Educação do Campo é uma construção histórica contemporânea. Dessa forma, faz-se necessário "dar voz" aos sujeitos que a estão edificando, metaforicamente, "tijolo a tijolo". Nesta construção, nos perguntamos sobre os desafios e enfrentamentos que tiveram que transpor, diante da realidade do campo no contexto da sociedade brasileira, mais especificamente no Estado do Tocantins.

Assim, analisamos os testemunhos de docentes da LEdoC da UFT, o que nos permitiu o desvelamento das suas percepções, concepções, desafios e enfrentamentos na implementação da LEdoC da UFT, assim como a construção das categorias para o deslindamento da trajetória de cada um, à luz das referências teóricas e de toda a riqueza e singularidade expressos nos relatos enunciados.

De acordo com Alberti (2010, p. 129), é difícil reproduzir o que o entrevistado diz com todo o sentido da sua expressão sem recorrer as suas próprias palavras, a “'trechos citáveis', unidades narrativas, [relatos que] dificilmente podem ser 'traduzidos', ou explicados de outra forma. O que eles revelam sobre a realidade é resultado do trabalho da linguagem em produzir racionalidade".

\section{Os Sujeitos e os Contextos da LEdoC}

Os sujeitos desta pesquisa são cinco professores da UFT que participaram do processo de implantação do Curso de Licenciatura de Educação do Campo nos campi de Arraias e Tocantinópolis. Do campi de Arraias, foram entrevistados: a) Pimenta, coordenador da LEdoC no momento da pesquisa; b) Messias, professora na LEdoC; e c) Santana, integrante do grupo de docentes que elaborou o PPC da Licenciatura em Educação do Campo para este campi.

No campi de Tocantinópolis, realizaram-se entrevistas com: a) professora Almeida, docente no LEdoC e coordenadora do grupo de pesquisa GEPE da UFT (Cultura política, da Linha de pesquisa Movimentos Sociais, educação e questões agrárias, campi de Tocantinópolis); e b) Oliveira, coordenador do curso.

Os entrevistados - ao narrar a realidade vivenciada sob sua ótica - revelam toda a trama da realidade em que a sua história de vida, pessoal e profissional foi formada, a qual, por vezes, constitui- 
se em um amálgama da sua própria existência. Neste caso, é pautada nos ideais e no comprometimento com a construção de um novo projeto de desenvolvimento do campo, que perpassa a formação de professores em uma licenciatura específica para a Educação do Campo, o que pode ser constado na fala do Professor Oliveira:

Eu tive muito contato com os sindicatos dos trabalhadores e trabalhadoras rurais e com a Federação da Agricultura Familiar, a Fetraf, então [pausa] sempre com a postura de defender o campesinato, sempre com a postura contrária ao agronegócio. E, ideologicamente, sempre assumi essa linha, e foi essa trajetória de combate ao agronegócio, latifúndios, de defesa da reforma agrária que me trouxe para a Educação do Campo. (OLIVEIRA, 2015, informação oral ${ }^{3}$ ).

O envolvimento de Oliveira (2015) com as questões agrárias, desde sua juventude, repercute na sua concepção de educação voltada para a população campesina, em um contexto de luta contra as forças hegemônicas. Este posicionamento nos remete às discussões feitas por Fernandes e Molina (2004, p. 39), quando afirmam que:

O paradigma da Educação do Campo nasceu da luta pela terra e pela reforma agrária. Afirmamos que esta luta cria e recria o campesinato em formação no Brasil. Desse modo, a Educação do Campo não poderia ficar restrita aos assentamentos rurais. Era necessária a sua espacialização para as regiões, para as comunidades da agricultura camponesa.

A professora Santana nos conta que atua na UFT, campi de Arraias, desde 2010, e seu primeiro contato com populações rurais se deu quando fazia a graduação, em 1999, período em que teve experiências em assentamentos rurais, onde pesquisava sobre a educação ofertada nestes locais.

A professora Messias chegou ao campi da UFT de Arraias no início de 2014, no período da divulgação do vestibular para o ingresso da primeira turma da LEdoC, e está vivenciando o processo de implementação do curso. Ela nos revela que exercer o magistério na LEdoC é uma realização pessoal e profissional, porque vai ao encontro de suas experiências como militante do movimento contra a construção de barragens e de trabalhos desenvolvidos junto aos povos indígenas e em comunidades quilombolas. Considera que a sua atuação na militância desses movimentos facilita a compreensão da diversidade cultural existente no Estado do Tocantins.

O professor Pimenta nos informa que atua no magistério superior há 10 anos e, a partir de 2013, veio "redistribuído" da Universidade Federal do Piauí (UFPI) para a UFT, campi de Arraias. Na UFPI, já trabalhava com a Educação do Campo, quando, em 2008, a universidade participou do edital do Procampo. De acordo com o professor, a Educação do Campo deve buscar:

[...] o diálogo da cultura local com a cultural universal e possibilitar então uma formação crítica. Resgate só da cultura local não dá pensamento crítico a ninguém! Só 
dá eugenismo, só dá hipervalorização descontextualizada da cultura local. Inversamente também, se você tiver uma formação extremamente universalista da cultura local, você não tem o olhar para a cultura local, [...] a cultura local se perde, especialmente aquilo que ainda não está registrado, que nós encontramos nos testemunhos e em práticas sociais que vão se perdendo. (PIMENTA, 2015, informação $\left.\mathrm{oral}^{4}\right)$.

A professora Almeida, pernambucana, ingressou na UFT, campi de Tocantinópolis, em 2010, como docente no curso de Ciências Sociais. E, ministrando as disciplinas de Movimentos Sociais, Desenvolvimento Regional e Geografia da Amazônia, teve a oportunidade de conhecer a realidade do Estado do Tocantins.

Essas informações coletadas com os entrevistados demonstram sua relação pessoal e profissional com a LEdoC, seja através de experiências como docentes e pesquisadores, seja enquanto pessoas.

A LEdoC da UFT é uma experiência nova, em desenvolvimento, e a sua implantação, a exemplo do que ocorreu em outras instituições públicas, foi permeada de conflitos e tensões em face da proposição de um novo modelo de curso, que difere em concepção e formato daqueles que tradicionalmente são ofertados nas universidades brasileiras.

O grupo de professores que articulavam a proposta - nas discussões travadas para os encaminhamentos e construções da proposição do curso - definiu que esta deveria atender às peculiaridades da população rural da região, por isso a escolha da área de Artes.

Santana (2015) lembra que tais discussões se davam também com um grupo de professores do campi de Tocantinópolis, pois a intenção era que ambos os campi respondessem ao edital do Procampo, com a mesma proposição de curso.

Outro ponto importante destacado por Santana (2015) refere-se à perspectiva identitária da população campesina da região de Arraias, formada por também por comunidades quilombolas. Na compreensão da professora, além da garantia do direito à Educação Superior aos sujeitos coletivos que compõem a população do campo, o curso possibilita, em sua área de formação, a valorização da riqueza cultural manifestada por essas comunidades.

De acordo com Pimenta (2015), em âmbito local, havia demanda para implantação de cursos que atendessem às necessidades de camponeses, quilombolas, ribeirinhos, indígenas e demais comunidades tradicionais. A partir da publicação do edital, conversou-se com lideranças das comunidades para a implantação da LEdoC. 
Em Tocantinópolis, o processo de implantação da LEdoC não se deu de forma tranquila. Na ocasião, foram expostos os conflitos e tensões existentes tanto no interior do campi quanto nas relações entre ele e a comunidade, conforme o relato de Oliveira (2015):

O que nós sabemos é que foi muita luta para se ter o curso aqui em Tocantinópolis, não foi fácil. Resistência dentro do campi, resistência na comunidade, e, somada a tudo isso, uma disputa política interna no campi [...]. Era uma disputa natural pela hegemonia do campi. E, na universidade, muitas vezes, essas disputas não dão coisa boa, não, na maioria das vezes.

Quando Oliveira (2015) ingressou na UFT em Tocantinópolis, o processo de implantação já estava na fase de elaboração do PPC, que ele avalia da seguinte forma: "tínhamos um período muito rápido pra gente terminar o PPC para aprovação e até mesmo não ficou um PPC muito legal; nós não fazemos uma boa avaliação do nosso PPC. Foi um PCC que foi feito para aprovação, nas marras".

As resistências encontradas na comunidade para implantação da LEdoC desvelam a dificuldade de se romper com o que está posto na realidade educacional brasileira, que repercute no meio acadêmico: a "valorização" de cursos considerados importantes pelo mercado. Propor um curso que visa à formação de educadores do campo não representa os interesses dos grupos dominantes, ocasionando os conflitos descritos pelos professores.

Esta visão de universidade como lugar privilegiado de produção de conhecimento avançado para as elites entrou em crise e é apontada por Barbosa (2012, p. 27) como "isoladas das demais, e são fundadas na dicotomia entre alta cultura/cultura popular, educação/trabalho, teoria/prática". É na ruptura do paradigma dominante que a Educação do Campo se assenta, o que na luta dos movimentos sociais pela ocupação de seu lugar no processo de produção do conhecimento científico significa para a "universidade pública um momento de transição oportuno para que se abra um espaço de escuta das experiências e saberes destes movimentos, e a universidade possa constituir-se como espaço de diálogo" (BARBOSA, 2012, p. 25).

Conforme o relato de Almeida (2015, informação oral ${ }^{5}$ ), as discussões foram fundamentais para os encaminhamentos, que culminaram com a implantação da LEdoC na UFT. Fomentaram a percepção que o momento era propício para efetivação da proposta. Com isto, aprofundou-se o debate sobre a Educação do Campo na perspectiva do Ensino Superior, com um forte diálogo envolvendo os movimentos sociais da região do Bico do Papagaio, conferindo-lhes um papel essencial na efetivação dessa política pública.

Todo o processo de implantação da LEdoC foi marcado por enfretamentos e oposições ao curso dentro da própria universidade e, ultrapassando seus muros, ganhou uma dimensão inimaginável. As 
tensões e conflitos configuram uma possibilidade quase inevitável quando se trata de reivindicar políticas públicas que instituem direitos sociais, no caso, assegurar o direito à educação da população que tem o campo como meio de existência, produção e vida.

Neste sentido, essas reivindicações representam uma forte ameaça às forças hegemônicas que controlam o meio rural por meio do agronegócio, expropriando e excluindo os sujeitos que lá residem. A LEdoC também traz elementos que nem sempre são entendidos em sua conjuntura, no sentido de sua novidade político-pedagógica e epistemológica, ocasionando, na comunidade e no próprio espaço acadêmico, resistências à sua implantação.

A busca pelo direito à educação dos povos do campo, muitas vezes, é restrita e não os alcança se não houver uma luta constante e incessante pautada nos princípios que regem a Educação do Campo. A esse respeito, Molina (2011, p. 353) advoga:

Apesar das dificuldades enfrentadas para sua implantação e funcionamento, entendemos que a Licenciatura em Educação do Campo tem um relevante potencial de contribuir com a melhoria dos processos de ensino e aprendizagem dos sujeitos do campo, principalmente pelo fato de estar trabalhando com educadores que vêm desta mesma realidade e que conhecem as dificuldades e as condições reais de vida de seus educandos, os jovens do campo, e também porque a estratégia formativa proposta da articulação por áreas do conhecimento realmente possibilita a construção da organização de trabalhos pedagógicos que se articulam em torno de questões da própria realidade.

A LEdoC ainda causa espanto e estranheza o meio acadêmico, por sua proposição e formato, porque defende que a formação humana não é universal, homogênea, mas pode resultar das tensões entre diversidades e desigualdades.

Os posicionamentos dos professores refletem as diferentes concepções de educação pretendidas para a LEdoC. Todavia demonstram preocupação na construção da identidade própria para os educadores que vão atuar no curso, de modo a fazer com que estejam comprometidos com a realidade política, social, econômica e cultural da população que vive no e do campo.

Neste sentido, Silvanete Pereira dos Santos (2012, p. 46) argumenta que é importante refletir sobre o modelo de educação que está sendo ofertado aos camponeses, e que a licenciatura específica para a "formação do professor que atua na escola rural instaura um novo elemento no âmbito da discussão teórica, que nos permite refletir a respeito da extensão e profundidade do termo 'Educação Superior', articulando-a com as questões da Educação do Campo".

\section{A LEdoC da UFT e os movimentos sociais}


Este estudo já evidenciou a importância dos movimentos sociais na construção desse novo paradigma da Educação do Campo. No entanto, nesta análise, buscamos apresentar o papel desempenhado por estes movimentos na criação da LEdoC na UFT, na luta contra a hegemonia presente no campo no estado do Tocantins.

Os PPCs da LEdoC dos campi de Arraias e Tocantinópolis - embora tenham sido elaborados para uma mesma finalidade, com muitas referências teóricas em comum, trazendo no bojo da sua proposta a mesma área de formação - evidenciam as diferentes concepções de Educação do Campo que possuem seus elaboradores, especialmente por ocasião da implantação e implementação dos cursos.

O entendimento do grupo proponente dos cursos é o de que a LEdoC propicia condições para o empoderamento dos camponeses, ao mesmo tempo em que atende às demandas dos movimentos sociais na região do Bico do Papagaio (em Tocantinópolis) e de comunidades quilombolas na região Sudeste do Tocantins e Norte Goiano (em Arraias). Uma vez que a musicalidade se expressa fortemente tanto nas comunidades quilombolas como nas indígenas, com o intuito de potencializar as expressões culturais dessas localidades, optou-se, então, pela implantação dos cursos na área de Códigos e Linguagens, mais precisamente em Artes e Música.

No que concerne às relações da LEdoC com os movimentos sociais, no que diz respeito à existência destes e das licenciaturas estarem relacionadas às demandas da sociedade, Santana (2015) faz uma importante reflexão:

Tanto Arraias quanto Tocantinópolis têm características muito parecidas de serem menores campi. Temos essas questões relacionadas às comunidades rurais muito forte. Lá em Tocantinópolis, tem um diferencial, que os movimentos sociais são mais presentes, mais relacionados com a Universidade; aqui a gente ainda está construindo. Eu acho que leva tempo também para isso. (SANTANA, 2015, informação oral ${ }^{6}$ ).

De acordo com Oliveira (2015), a LEdoC do campi de Tocantinópolis possui uma estreita ligação com os movimentos sociais: “o MAB [Movimento dos Atingidos por Barragens] e o MST [Movimento dos Trabalhadores Rurais Sem Terra] [...] são coautores do nosso PPC, inclusive. Eles são coautores da nossa proposta pedagógica".

Almeida (2015) reconhece que, da luta dos movimentos sociais pela conquista da terra, deriva a reivindicação por uma educação específica para os camponeses, para que se faça respeitar o direito a um curso de formação de professores que leve em conta a realidade do espaço do campo e dos sujeitos que nele residem, nas suas dimensões sociais, culturais e políticas. Desta forma, o projeto pensado para a LEdoC de Tocantinópolis busca atender às demanda educacionais dessas populações, sejam elas 
formadas por quilombolas, assentados pela Reforma Agrária, comunidades da agricultura familiar ou por populações tradicionais.

Das tensões e conflitos vivenciados durante o processo de criação da LEdoC em Tocantinópolis, Almeida (2015) ainda acrescenta que:

Moramos no Bico do Papagaio, [localidade] com um índice de desenvolvimento humano baixíssimo. O [Índice de Desenvolvimento da Educação Básica] IDEB baixo, o índice de analfabetismo elevado, e aí as bandeiras de luta: derrubar um projeto que vai trazer um pouco? Temos uma dívida com os camponeses do Bico, então vamos educar, formar esses professores atuar para o campo. Então, a grande questão é: nós temos um curso de Pedagogia que forma professores. Mas não éramos nós que dizíamos que não tínhamos, eram os camponeses que diziam que queriam curso de Educação do Campo.

A ênfase dada pela professora revela a importância atribuída à LEdoC para a construção de conhecimentos que assegurem os direitos reivindicados pelos movimentos sociais - como o direito à educação e à terra -, direcionando sua análise a partir do conceito de território apregoado por Fernandes e Molina (2004, p. 1), quando afirmam que "território deve ser definido como espaço político por excelência, campo de ação e poder, onde se realizam determinadas relações sociais".

Para os sujeitos entrevistados, a LEdoC da UFT representa a contra-hegemonia, na medida em que busca contribuir com a transformação social, tendo em vista a construção de um novo projeto de sociedade e de desenvolvimento do campo:

O histórico de lutas agrárias aqui é muito grande, e o desafio de encampar o curso de Educação do Campo aqui no Bico do Papagaio é uma contra-hegemonia muito forte. E queremos dizer assim: olha, estamos aqui, no olho do furação, no meio dos conflitos de terras, assumindo um lado, assumindo o lado dos mais fracos, assumindo o lado das pessoas que realmente necessitam. Então, ideologicamente, o curso de Educação do Campo, ele tem uma força política de intervenção no dia a dia, no social e de transformação da realidade. (OLIVEIRA, 2015, grifos nossos).

No entendimento dos professores, um dos desafios da LEdoC é fazer com que os envolvidos na implementação do curso tenham clareza sobre a proposição dessa licenciatura, que a concebam como uma ferramenta que possibilitará o acesso dos sujeitos do campo a uma formação orientada pela sua própria práxis social, articulada aos movimentos sociais, capaz de se contrapor às estruturas hegemônicas presentes na sociedade.

\section{Epistemologias e concepções imbricadas na LEdoC}


Para Barbosa (2012), o desafio da LEdoC não se encontra apenas na especificidade dos seus sujeitos, mas se inicia na materialidade de origem da Educação do Campo, que, por sua vez, não corresponde a uma proposta pedagógica para as escolas do campo. Sendo assim, o desafio da LEdoC não está na organização do trabalho pedagógico em si.

A implementação da LEdoC, com o seu formato inovador, desvela as tensões e os desafios enfrentados pelos sujeitos que a estão materializando, desde a elaboração dos PPCs até a sua institucionalização. Segundo Oliveira (2015), mesmo novo, o PPC precisa ser revisado, "porque ele foi construído a toque de caixa, porque tinha o prazo do edital do MEC, que tinha que ser cumprido". O professor menciona já constar no PPC a perspectiva da alternância e que o curso tem que ocorrer em período integral, voltado para a Educação do Campo e sua importância; afirma que há disciplinas sobre os movimentos sociais e as questões agrárias, além das “disciplinas de letramento e as disciplinas ligadas à arte e à música, que é a habilitação dele”. No entanto alguns aspectos precisam ser desenvolvidos, menciona.

Oliveira (2015) reconhece que, nas circunstâncias em que foi elaborado, o PPC não favoreceu o detalhamento epistemológico ou mesmo das concepções a serem desenvolvidos na LEdoC, mas esclarece que, na prática do dia a dia, isto está sendo revisto, com base nos pilares que dão sustentação à Educação do Campo.

Messias (2015, informação oral ${ }^{7}$ ) considera essencial a inclusão de disciplinas que fomentem a reflexão sobre diversidade cultural, o respeito às diferenças. Segue argumentando que não apenas os estudantes devem aprender isto mas os professores também e considera ser essa uma das fragilidades do curso.

As falas dos entrevistados expõem a complexidade da construção das bases epistemológicas da LEdoC, processo que envolve (ou deveria envolver) todos os seus sujeitos, professores e estudantes, nas suas dimensões políticas, sociais, econômicas e culturais, em uma nova forma de construir conhecimento, vinculada aos interesses e às necessidades da população campesina.

A esse respeito Almeida (2015) salienta:

"Era esse o curso que os movimentos queriam." Não! Eles queriam [ciências] agrárias. Porque para eles é muito carente a discussão em agrárias no Tocantins, porque [elas, as ciências agrárias] trabalham especificamente mais para o agronegócio, e [os movimentos sociais] queriam fundar a discussão do campo com as agrárias. Inclusive tinha no Edital, mas nós não tínhamos corpo intelectual para aprovarmos o curso. Muitas vezes precisamos elaborar estratégias para ocuparmos a universidade. E é muito difícil ocupar a universidade no Bico do Papagaio, uma região de coronelismo. E isso está dentro da universidade e por dentro da universidade; isso está posto. Então, é muito complexa essa relação, e essa foi uma das condições que nós tivemos para ocupar. Então optamos por Música e Artes Visuais. (grifos nossos).

PERSPECTIVA, Florianópolis, v. 35, n. 3, p. 951-977, jul./set.. $2017 \quad$ http://www.perspectiva.ufsc.br 
Neste aspecto, Almeida evidencia que a LEdoC, no contexto do campi de Tocantinópolis, também representa uma estratégia de inserção dos movimentos sociais no território acadêmico, pautada na luta contra a hegemonia dos grupos sociais dominantes na região.

Para Pimenta (2015), a base epistemológica mais apropriada para a LEdoC é a histórico-crítica, na perspectiva marxista. O coordenador faz uma crítica ao ecletismo com que tem sido tratada a Educação do Campo. Essa concepção é compartilhada por vários autores, entre eles Bezerra Neto (2010, p. 150), para quem a educação pretendida pelos movimentos sociais apresenta alguns problemas na origem de sua formação, “ao aderir ao comunitarismo-cristão e ao pragmatismo, consubstanciado num ecletismo pedagógico, fica impossibilitado de compreender a realidade a partir da relação dialética propugnada pelo materialismo histórico, que pretendem aderir".

Por outro lado, os docentes entrevistados explicitam:

Nós defendemos uma Educação do Campo que está pautada na interface dos saberes da cultura camponesa, do saber imaterial e da produção do conhecimento elaborado pelo ponto de vista da ciência da academia. [...]. Nós precisamos avançar nessa educação e tentar melhorar a vida das pessoas e pensar em outra alternativa de sociedade. (OLIVEIRA, 2015).

Então, é uma possibilidade de formação de professores, de acreditar que a gente produz conhecimento a partir das comunidades e dos seus saberes (ALMEIDA, 2015, grifos nossos).

$\mathrm{Na}$ opinião dos docentes, as bases teóricas que sustentam a Educação do Campo devem compreender as perspectivas dos movimentos sociais e, a partir delas, valorizar a cultura camponesa e a articulação entre os saberes acadêmicos e práticos.

É interessante salientar que os princípios que compõem uma determinada prática nos levam a sua melhor compreensão. Neste aspecto, as narrativas dos entrevistados nos possibilitam a percepção dos referenciais teóricos em que se embasam, que são o suporte para a materialização da LEdoC nos campi em que atuam.

Na relação dialética desses sujeitos com os movimentos sociais, emerge uma nova pedagogia de resistência, novas formas de construção do conhecimento, que, na concepção de Arroyo (2012, p. 15), podem ser compreendidas como:

Outras formas de pensar coladas a formas de reagir e intervir tão diferentes da lógica do pensar oficial, até escolar, que só valoriza pensar válido ir às causas, às múltiplas determinações do real. Seu pensar é outro construído a partir das múltiplas opressões e das consequências sociais, políticas de suas lutas, reações e resistências. Outros Sujeitos, outras Pedagogias. 
Assim, há de se considerar que estas "outras pedagogias” possibilitam aos sujeitos do campo a apropriação dos saberes necessários para a compreensão e intervenção nos processos sociais, políticos, econômicos e culturais em que estão inseridos.

É importante ressaltar a atenção dos sujeitos entrevistados para com a articulação entre os conteúdos ministrados e a prática social dos estudantes, ou seja, o conhecimento científico e a realidade em que os estudantes estão inseridos. Para tanto, discorreram sobre os diferentes tempos formativos que compõem a organização do trabalho pedagógico:

Temos discutido sobre a alternância nas reuniões de colegiado. É um grupo ainda pequeno, e cada um possui seus conhecimentos. É o primeiro semestre da primeira turma [pausa]. No tempo-comunidade, várias coisas ficaram a desejar, mas acho que neste semestre têm melhorado. Tem que ser alternância de saberes; temos que ter isso muito claro [pausa]. Acho que são algumas das resistências, as tensões; [...] tem acontecido, mas ainda temos muito que avançar. E aí, claro, nas reuniões, um não concorda com uma coisa, e aí sempre a opinião de alguns prevalece. E tem muito a avançar nessa questão da alternância. São tantos tipos de alternância [pausa]. Mas acho que ela tem que primar pela particularidade do lugar, pela especificidade do lugar; não dá pra você ficar copiando de outro lugar. Temos que pensar no local. E junto com os estudantes, o que é fundamental [pausa], que tenha a participação dos estudantes. Que os estudantes se envolvam nesse processo. Então, tudo é um desafio. E precisa ser superado, vencido [pausa]. (MESSIAS, 2015).

As palavras de Messias nos remetem à ideia de que desafios ainda precisam ser vencidos na organização dos tempos formativos na LEdoC, tanto no que se refere à própria articulação desses tempos quanto na proposição de um trabalho pedagógico integralizado do coletivo de docentes; além de ser "imprescindível a vinculação dos processos de ensino-aprendizagem com as condições concretas de vida desses futuros educadores e de seus educandos, sujeitos do campo, em luta pela garantia da manutenção desta identidade" (MOLINA, 2011, p. 349).

Pimenta (2015) defende na alternância a interação entre o conhecimento universalmente construído pela humanidade e o conhecimento local, em um processo de desenvolvimento da práxis e da reflexão epistemológica. Sua fala reflete a intenção de que, durante os tempos formativos, sejam feitas aproximações teóricas com a realidade concreta dos estudantes. Porém reconhece alguns entraves na condução da alternância e aponta que é preciso

[...] darmos condições materiais para que esse grupo de professores trabalhe; [...] quando eu falo "esse grupo" [são] as pessoas no Brasil envolvidas com Educação do Campo, sejam eles professores ou técnicos administrativos, mas que tenham condições para fazer o seu deslocamento. Quando falo de deslocamento, estamos falando em ter carro, motorista, de ter carro às vezes traçado, por que tem lugar que não dá pra ir com carro pequeno. E isso daí são condições materiais que a universidade deve fornecer. Só que a universidade recebe esses financiamentos do governo, em um ano de crise como esse ano de 2015, onde tudo está sendo cortado. Cortar gasto com a Educação do 
Campo significa comprometer a formação, mas comprometer de modo muito forte. Nesse sentido, se nós conseguirmos [é porque] estamos fazendo um trabalho conjunto pra superar essas dificuldades. (PIMENTA, 2015).

As dificuldades estruturais apontadas por Pimenta, embora não sejam fatores determinantes, podem comprometer, em muitos aspectos, o acompanhamento aos estudantes no Tempo-Comunidade, prejudicando a organização do trabalho pedagógico do curso, tendo em vista os objetivos preceituados para este tempo-espaço formativo, no sentido de dar suporte para o encaminhamento das atividades e para o planejamento de ações que levem os alunos à intervenção concreta na realidade local em que vivem.

O Tempo-Comunidade é ainda uma incógnita para muitos docentes da LEdoC. Em termos práticos, constitui-se em seu maior desafio. Oliveira nos relata as experiências vivenciadas no campi de Tocantinópolis, das quais emergem alguns questionamentos:

A alternância é o grande gargalo, porque precisa de um calendário diferente, uma estrutura de sistema de informática diferente no nosso diário eletrônico; ele tem que ser diferente dos demais, mas não pode ser rígido como os outros. As nossas aulas são em período integral, o que dá uma diferença enorme com as demais aulas de um curso diferente. Não tínhamos uma noção de como seria, porque uma coisa é a alternância na EFA [Escola Família Agrícola] [...]. Outra coisa é a alternância num nível superior. E os instrumentos que vão utilizar? Vão utilizar caderno da realidade? Ele faz efeito no Ensino Superior? Ele não faz? São questões que precisamos pensar. (OLIVEIRA, 2015, grifos nossos).

O posicionamento e as questões levantadas por Oliveira coadunam-se com os de Barbosa (2012, p. 141), quando ela diz que a alternância no Ensino Superior não trata apenas de transpor para a LEdoC um dos modelos e tipologias de alternância, nem de considerá-la apenas como tempos alternados de processos formativos. Levando-se em conta que as experiências de alternância no Brasil se deram no Ensino Médio, ela se faz novidade do Ensino Superior. Nesta perspectiva, a autora conclui que seria preciso construir uma "proposta de alternância para a formação de professores em nível superior, atendendo às especificidades do contexto universitário dos sujeitos (já adultos) e às demandas dos territórios em abrangência".

Segundo Oliveira (2015), no processo de construção pedagógica do curso, a equipe não tem medido esforços para implementar estratégias mais condizentes com a sua propositura, realizando as adequações necessárias para viabilizar a alternância na perspectiva do Ensino Superior. Afirma que a equipe faz uso de diversos instrumentos para registro desse processo e do preparo necessário para viabilizá-lo (oficina de história de vida; caderno de realidade; elaboração de memorial descritivo das pesquisas e de relatórios de pesquisa). 
Para além das idas e vindas às comunidades, a alternância, por sua complexidade, necessita de uma constante reflexão sobre as práticas que a constituem, e o diálogo é parte imprescindível para sua consecução. Da fala de Oliveira (2015), pressupomos que os arranjos estão se firmando; os sujeitos vão construindo estratégias que possibilitam a efetiva articulação e inter-relação entre os diferentes saberes por meio da alternância, dando vida a um modelo que atenda às expectativas e necessidades dos estudantes da LEdoC.

Sobre esse processo, Chartier (1986 apud SILVA, 2012, p. 181) postula que a "verdadeira alternância é estreita articulação entre os meios envolvidos na formação numa perspectiva de mão dupla, relacionando seus conteúdos, complementando-os e enriquecendo-os reciprocamente". Esse é um dos maiores desafios da LEdoC: realizar a verdadeira alternância.

Em suma, cada coletivo de professores constrói mecanismos para que os obstáculos sejam superados, e a lógica diferenciada dos Tempo-Comunidade e Tempo-Universidade suscita ainda muitas dúvidas no direcionamento de ações que possibilitem a construção do conhecimento dentro da dinâmica de espaços e tempos formativos.

\section{Considerações Finais}

Das conquistas enunciadas pelos movimentos sociais do campo, foi possível apreender os marcos legais que reconhecem e legitimam os direitos voltados para a educação da população que vive no e do campo. Parte desta conquista, a LEdoC constitui um avanço, mas a sua efetivação necessita ser reivindicada constantemente.

Em que pesem os aspectos gerais abordados, constatamos que eles diferem em suas concepções epistemológicas e pedagógicas, conforme evidenciado na composição dos elementos preconizados para a implantação do curso em cada campi. Embora a abordagem seja tímida em ambos os documentos, identificamos que a LEdoC de Arraias é voltada para o viés histórico-crítico, enquanto em Tocantinópolis adota-se uma postura freiriana, o que foi confirmado nos relatos dos entrevistados.

As narrativas dos entrevistados são histórias construídas pela percepção de cada sujeito, impregnadas das suas experiências pessoais e profissionais, sejam elas constituídas na participação nos movimentos sociais do campo, no exercício da docência no Ensino Superior, na concepção de Educação do Campo, as quais dão testemunho de como o presente se compôs e, consequentemente, de como a LEdoC se firma nos campi de Arraias e Tocantinópolis. 
A diversidade intercultural existente no meio rural no estado do Tocantins - devido a sua constituição por indígenas, quilombolas e camponeses - propicia mais um desafio para a materialização da LEdoC, na medida em que a formação dos docentes não abrange todas as especificidades requeridas por cada uma dessas populações. Acreditamos que este fator também é processual, e, aos poucos, a UFT, no âmbito da LEdoC, está buscando estratégias para que se construam, dentro da academia, novas formas de produção do conhecimento, voltadas para esses diferentes sujeitos.

Assim, a LEdoC vem sendo construída na UFT - nos campi de Arraias e Tocantinópolis - com diferentes vertentes epistemológicas, com diferentes concepções e diferentes sujeitos. A aceitação das especificidades facilita que todas as diferenças sejam respeitadas, inclusive uma educação voltada para a formação específica de professores do campo, com práticas políticas e curriculares voltadas para a cultura local, que atendem às necessidades dos sujeitos que têm no campo um espaço de produção, de existência e de vida.

\section{Notas}

${ }^{1}$ Citado por Caldart (2011), registro da exposição apresentada pela Coordenação Geral de Educação do Campo (CGEC) à Câmara Temática de Formação de Professores do MEC, em sessão no dia 07 de abril de 2006 e depois incorporados aos documentos de proposição do curso.

2 Recorte da dissertação intitulada "Percursos e desafios da Licenciatura em Educação do Campo na UFT", defendida em 2015, mestrado de Educação da Universidade Federal do Tocantins.

${ }^{3}$ OLIVEIRA, Ubiratan Francisco de. Entrevista IV. [24 jun. 2015]. Entrevistadora: Darlene Araújo Gomes. Tocantinópolis, TO, 2015. 1 arquivo .mp3 em posse dos autores. Docente do curso desde 2013. Todos os relatos de Oliveira utilizados neste artigo dizem respeito à entrevista em questão.

${ }^{4}$ PIMENTA, Alessandro Rodrigues. Entrevista I. [19 maio 2015]. Entrevistadora: Darlene Araújo Gomes. Arraias, TO, 2015. 1 arquivo .mp3 em posse dos autores. Docente do Curso desde 2013. Todos os relatos de Pimenta utilizados neste artigo dizem respeito à entrevista em questão.

${ }^{5}$ ALMEIDA, Rejane Cleide Medeiros de. Entrevista V. [26 jun. 2015]. Entrevistadora: Darlene Araújo Gomes. Marabá, PA, 2015. 1 arquivo .mp3 em posse dos autores. Docente do campi desde 2010. Todos os relatos de Almeida utilizados neste artigo dizem respeito à entrevista em questão.

${ }^{6}$ SANTANA, Ana Camem. Entrevista III. [20 maio 2015]. Entrevistadora: Darlene Araújo Gomes. Arraias, TO, 2015. 1 arquivo .mp3 em posse dos autores. Docente do curso de Pedagogia desde 2010. Todos os relatos de Santana utilizados neste artigo dizem respeito à entrevista em questão.

${ }^{7}$ MESSIAS, Noeci Carvalho. Entrevista II. [20 maio 2015]. Entrevistadora: Darlene Araújo Gomes. Arraias, TO, 2015. 1 arquivo .mp3 em posse dos autores. Docente do curso desde 2014. Todos os relatos de Messias utilizados neste artigo dizem respeito à entrevista em questão. 


\section{REFERÊNCIAS}

ALBERTI, Verena. Narrativas pregnantes como jogos de linguagem: possibilidades da história oral à luz da teoria de Wittgenstein. UFC - Miolo, 2010.

ALMEIDA, Rejane Cleide Medeiros de. Entrevista V. [26 jun. 2015]. Entrevistadora: Darlene Araújo Gomes. Marabá, PA, 2015. 1 arquivo .mp3 em posse dos autores.

ARROYO, Miguel Gonzalez. Outros Sujeitos, Outras Pedagogias. Petrópolis, RJ: Vozes, 2012.

BARBOSA, Anna Izabel Costa. A organização do trabalho pedagógico na Licenciatura em Educação do Campo/UnB: do projeto às emergências e tramas do caminhar. Brasília, 2012. 351 f. Tese (Doutorado em Educação) - Universidade de Brasília, Brasília, 2012.

BEZERRA NETO, Luís. Educação do Campo ou Educação no campo? Revista HISTDBR on-line, Campinas, no 38, p. $150-168$, jun. 2010.

BRASIL. Conselho Nacional de Educação. Câmara de Educação Básica. Resolução CNE/CEB nº 1, de 3 de abril de 2002. Diretrizes Operacionais para a Educação Básica nas Escolas do campo. Diário Oficial [da] Federativa do Brasil, Poder executivo, Brasília, DF, 9 abr. 2002. Seção 1, p. 32. Disponível em: <http://pronacampo.mec.gov.br/images/pdf/mn_resolucao_\%201_de_3_de_abril_de_2002.pdf>. Acesso em: 18 set. 2017.

CALDART, Roseli Salete. Licenciatura em educação do campo e projeto formativo: qual o lugar da docência por área? In: MOLINA, Mônica Castagna; SÁ, Laís Mourão (Orgs.). Licenciaturas em educação do campo: registros e reflexões a partir das experiências piloto. Belo Horizonte: Autêntica, 2011, p. 95-121.

DELGADO, Lucília de Almeida Neves. História oral e narrativas: tempo, memória e identidades. História Oral, n. 6, p. 9-25, 2003. Conferência da abertura do VI Encontro Nacional de História Oral da Associação Brasileira de História oral (ABHO).

FERNANDES, Bernado Mançano; MOLINA, Mônica Castgana. O Campo da Educação do Campo. In: MOLINA, Mônica Castagna; JESUS, Sonia Meire Azevedo de. (Orgs.). Por Uma Educação do Campo: contribuições para a construção de um Projeto de Educação do Campo. Brasília: Articulação Nacional "Por uma Educação do Campo", v. 5, 2004.

MENESES, Maria Adeilma. Pedagogia da terra e a formação e Professores para a Educação do Campo na UFS e UFRN. 135 f. Dissertação (Mestrado em Educação) - Universidade Federal de Sergipe, Faculdade de Educação, São Cristóvão, 2009.

MESSIAS, Noeci Carvalho. Entrevista II. [20 maio 2015]. Entrevistadora: Darlene Araújo Gomes. Arraias, TO, 2015. 1 arquivo .mp3 em posse dos autores.

MOLINA, Mônica Castgana. Expansão das licenciaturas em Educação do Campo: desafios e potencialidades. Educar em Revista, Curitiba, Brasil, n. 55, p. 145-166, jan./mar. 2015.

As políticas de educação do campo na universidade pública brasileira. Revista Congreso

Universidad. $\quad$ v. II, $\quad$ n. $2, \quad$ p. 1-13, 2013. Disponível $\quad$ em: $<$ http://www.congresouniversidad.cu/revista/index .php/congresouniversidad/article/download/199/970>. Acesso em: 15 de maio de 2015. 
O caminho aberto pelas experiências piloto: limites e possibilidades das Licenciaturas em Educação do Campo. In: MOLINA, Mônica Castgana; SÁ, Laís Mourão (Orgs.). Licenciatura em Educação do Campo. Belo Horizonte: Autêntica, 2011. p. 343- 355.

MOLINA, Mônica Castgana; SÁ, Laís Mourão; SÁ, Laís Mourão. A Licenciatura em Educação do Campo da Universidade de Brasília: estratégias político-pedagógicas na formação de educadores do campo. In: MOLINA, Mônica Castgana; SÁ, Laís Mourão; SÁ, Laís Mourão (Orgs.). Licenciatura em Educação do Campo. Belo Horizonte: Autêntica, 2011. p. 35- 61.

OLIVEIRA, Ubiratan Francisco de. Entrevista IV. [24 jun. 2015]. Entrevistadora: Darlene Araújo Gomes. Tocantinópolis, TO, 2015. 1 arquivo .mp3 em posse dos autores.

PIMENTA, Alessandro Rodrigues. Entrevista I. [19 maio 2015]. Entrevistadora: Darlene Araújo Gomes. Arraias, TO, 2015. 1 arquivo .mp3 em posse dos autores.

SANTANA, Ana Camem. Entrevista III. [20 maio 2015]. Entrevistadora: Darlene Araújo Gomes. Arraias, TO, 2015. 1 arquivo .mp3 em posse dos autores.

SANTOMÉ, Jurjo Torrres. Globalização e Interdisciplinaridade: o currículo integrado. Porto Alegre. Artes Médicas, 1998.

SANTOS, Silvanete Pereira dos. A concepção de alternância na Licenciatura em Educação do Campo na Universidade de Brasília. 2012. 163 f. Dissertação (Mestrado em Educação) - Faculdade de Educação, Universidade de Brasília, Brasília, 2012.

SANTOS, Clarice Aparecida. Educação do Campo e políticas públicas no Brasil: a instituição de políticas públicas pelo protagonismo dos movimentos sociais do campo na luta pelo direito à educação. 2009. 104 f. Dissertação (Mestrado em Educação) - Faculdade de Educação, Universidade de Brasília, Brasília, 2009.

SANTOS, Boaventura de Sousa. Para um novo senso comum: a ciência, o direito e a política na transição paradigmática. 8. ed. São Paulo: Cortez, 2011.

SANTOS, Sonia Maria dos; ARAÚJO, Osmar Ribeiro. História Oral: Vozes, Narrativas e Textos. Cadernos de História da Educação, n. 6, p. 191-201, jan./dez. 2007. Disponível em: <http://www.seer.ufu.br/index.php/che/article/view/282>. Acesso em: 20 jun. 2015.

SILVA, Lourdes Helena. As experiências de formação do campo: alternâncias ou alternâncias? Curitiba: CRV, 2012.

UNIVERSIDADE FEDERAL DE TOCANTINS. Projeto Pedagógico do Curso de Licenciatura em Educação do Campo. Arraias, 2013a. Mimeo.

UNIVERSIDADE FEDERAL DE TOCANTINS. Projeto Pedagógico do Curso de Licenciatura em

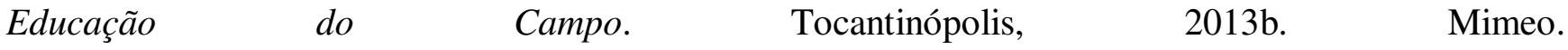




\section{Licenciature in rural education at UFT: perspectives and challenges in a course construction}

\begin{abstract}
We socialized a research on the Licenciature in Rural Education at the Federal University of Tocantins (UFT). We analyzed the implementation processes in their political and pedagogical aspects. We debated on the protagonism of social movements in the struggles for the right to education and to the questions directed to higher education policies for rural areas in Brazil. In the methodological way, we are inspired us in oral history, in the perspective of qualitative approach. We interviewed teachers who experience the course implementation process in the UFT, to grasp the expectations and constructions undertaken in the materialization of the Licentiate. The theoretical basis of this study was given by the dialogue with various theoretical as: Caldart, Santos, Molina, Arroyo, Silva, Alberti. We approach about the Pedagogy of Alternating as a reference to the desired switching to the Licentiate in Rural Education, as well, the propositions for its effectuation. We infer that the implementation of the Licentiate in Rural Education sets up an achievement for the population living in and field and is in process of construction, which demands, by its performers, new positions front to conflicts and confrontations for their effective materialization.
\end{abstract}

Keywords: Licentiate. Rural Education. Alternating.

\section{Darlene Araújo Gomes}

E-mail: LENEGOMES4@GMAIL.COM

\section{Idemar Vizolli}

E-mail: idemar@mail.uft.edu.br

Jocyléia Santana dos Santos

E-mail: jocyleiasantana@gmail.com
Licenciatura en educación del campo en la UFT: perspectivas y retos en la construcción del curso

\section{Resumen}

Socializamos una investigación acerca de la Licenciatura en Educación del Campo en la Universidad Federal de Tocantins (UFT). Analizamos los processos de implantación en sus aspectos políticos y pedagógicos. Hablamos a respeto del papel de los movimentos sociales en la lucha por el derecho a la educación y a las cuestiones dirigidas a las políticas de educación superior para las zonas rurales de Brasil. A lo largo del caminho metodológico, inspirámonos en la historia oral en la perspectiva de un enfoque cualitativo. Entrevistamos profesores que vivieron el processo de implantación del curso en la UFT, para aprehender las expectativas $y$ construcciones hechas en la realización de la Licenciatura. La base teorica de este estudio fue realizado atraves de la conversación con diversos teóricos como: Caldart, Santos, Molina, Arroyo, Silva, Alberti. Hemos hecho el abordaje acerca de la Pedagogía de la Alternância como una referencia a la conmutación deseada para la Licenciatura en Educación del Campo, así como sugerencias para su efetivación. Llegamos a la conclusión que la implantación de la Licenciatura em Educación del Campo representa un logro muy importante para el pueblo que vive en el y del campo y que se encuentra en proceso de construcción, lo que requiere, por parte de sus idealizadores, nuevas actitudes delante de los conflitos y enfrentamientos para su materialización efectiva.

Palabras clave: Licenciatura. Educación del Campo. Alternância.

Enviado em: 05/08/2016

Versão final recebida em: 03/05/2017

Aprovado em: 04/05/2017 